\title{
The (Im)possibility of Child Sexual Rights in South African Children's Account of HIV/AIDS
}

\section{Deevia Bhana}

\section{Introduction}

Over 5 million South Africans are currently infected with HIV/AIDS, with women and young girls (aged 15-24) facing greater levels of infection (UNAIDS 2005). One of the primary strategies in the fight against HIV/AIDS is to safeguard the rights of those who are infected and who are at risk of infection. But the rights of young children are often peripheral to these strategies. This is because HIV/AIDS necessarily invokes sexuality, and sexuality and associations of sexuality and young people are usually considered problematic. Around the world, the question of child sex rights produces deep anxiety and is hotly contested (Waites 2005). Rarely does scholarship link children, sex, HIV/AIDS and rights (Silin 1995). Hegemonic versions of childhood view sexual knowledge as polluting innocence (Renold 2005). Such attitudes presuppose a developmental view: sexuality and sexual rights is an accomplishment of maturity and the preserve of the adult world (James et al. 1998).

Child rights discourse calls for children to be treated as autonomous individuals. While they may benefit from adult protection, this discourse views them as capable, interactive social agents who engage with people and institutions (Prout 2000). The notion that children have rights which are not necessarily realised or claimed by all children has guided contemporary approaches adopted by UNICEF to development programming. Arguing for a 'Human Rights Approach' to development programming, UNICEF (2003) argues against development programmes based on agencies determining in advance the needs of children, and for more participatory approaches which focus on children having rights and being able to have their opinions taken seriously. Yet the voices of children in much research on early childhood, especially in so-called 'developing' countries, are usually mute. Even research which is informed by a concern for children's rights often addresses children as relatively passive, desexualised beings without the capacity to formatively and constitutively engage with sexual matters. There is very little information on the ways children themselves construct their knowledge of HIV/AIDS and sexualities, their freedoms and lack of freedoms, and whether and if so how they draw on rights discourses.

This article argues that exploring children's understandings of HIV/AIDS from the perspective of 'rights' can open a space through which to move beyond commonly found representations of the African child as being either simply a victim of HIV/AIDS or as a subject instrumentally exerting new 'rights' brought by South Africa's democracy. Based on a study of seven- and eight-year-old children's understandings of AIDS in a black township school in KwaZulu-Natal, South Africa, this article shows how boys and girls spoke about sexuality and HIV/AIDS and how, through this, they contested, affirmed and resisted rights. The research is influenced by a deep commitment to the rights of children to articulate their views and emotions and to be heard and taken seriously. Using ethnographic methods and group interviews, the research explored the extent to which sexuality characterised young children's narratives in a context of a severe AIDS epidemic. Rather than seeing children as victims, this research shows how in exercising, negotiating and adjusting what they see as their rights, children can be encouraged to raise and discuss issues about sexuality and about 'rights'. Allowing children to talk about such sensitive issues, this article argues, enables them to express themselves as sexual agents. 


\section{Race, class, gender in South African AIDS}

South African AIDS is gendered and racialised. Apartheid and a racialised migrant labour system have worked to destabilise family structures and fuel the HIV/AIDS epidemic (Phillips 2004). At the heart of South African AIDS is gender inequalities and there is considerable gender disparity in the rates of infection. The province of KuaZulu-Natal, where this research was conducted, has experienced some of the highest levels of infection in the country, with one-third of pregnant women now infected (Department of Health 2005). Young women's vulnerability to HIV/AIDS is increased by gender violence, rape and the gendered nature of their roles within heterosexual relationships (O'Sullivan et al. 2006). The current context in post-apartheid South Africa has seen rising unemployment and social inequalities, which has exacerbated HIV prevalence rates, especially amongst black men and women.

Combined with the history of apartheid and black male migrancy, the enduring racialisation of poverty vividly materialises in the context of informal settlements in which the children in this study live. Ominously, the demographic patterns of HIV mean that people in poverty (and in South Africa, they are predominantly black) bear a disproportionate burden. Informal settlements are rooted in unequal provision of housing for blacks under apartheid and have mushroomed in urban areas; they are a testimony of the failure of the new government to provide adequate housing to the poor. These settlements have the highest rates of infection and the children here are at most risk of HIV/AIDS. The home context for many children is characterised by one roomed shacks or imijondolos that are occupied by several people. Many children live in households where a parent or caregiver is HIV-positive and where children are caregivers to parents. There are about 300,000 AIDS orphans and numbers are expected to grow. There are no accurate figures for the number of children between zero and nine years old that are infected with AIDS. The majority of infections occur through infected mothers during pregnancy or through breastfeeding (Whiteside and Sunter 2000). The extent to which sexual abuse contributes to HIV infection is not known, but the myth that sex with young children cures AIDS increases children's vulnerability.

Young children's emerging meanings of HIV/AIDS and sexuality are embedded within the broader context of South African AIDS and the specific social and cultural systems which shape and are important in shaping the structure of experience of sexuality. As HIV/AIDS decimates thousands of people, particularly those in informal settlements, there is increasing openness in sexual speech and overwhelming visibility of sex and HIV/AIDS education and prevention - to such an extent that many have become 'sick of AIDS' (Mitchell and Smith 2003). It is possible to argue quite easily that young children emerging from these social worlds are victims whose rights have not been realised particularly with poor provision of housing and poverty. I argue, however, that we must resist the tendency to view the African child as innocent victims of HIV/AIDS and poverty.

The question of HIV/AIDS, childhood sexuality and basic autonomy for young children remains complex but must be seen within the broader cultural context and general surveillance of childhood sexuality. As I will illustrate, children's sexualities are nuanced by gender, racial and class differences in identity and power. Children's emerging sexualities are redolent of their readings of the South African landscape where power, wealth and health are so unevenly distributed in terms of these identities. In attending closely to the experiences of young children, the studies confirm that childhood sexualities can only be understood in relation to and, as part of, wider social relations. To understand childhood sexuality it is important to go beyond sexuality. It is precisely for this reason that age/race/ class/gender plays such an important role in the analysis of childhood sexualities.

\section{Constructing sexual rights in the context of HIV/AIDS}

How do young children construct knowledge of HIV/AIDS especially when sexuality is seen as problematic? The literature on sexual rights and young people often constructs children primarily in terms of rights to protection especially from sexual abuse and sexual contamination, while bodily autonomy and sexual knowledge and behaviour are generally seen as only applying to adults (Waites 2005). Recent years have seen shifts in knowledge of children's sexuality. Many commentators in the new sociology of childhood argue that children must be understood and accepted as sexual, rather than for their sexuality to be ignored and hidden (Weeks 2000). In South Africa there is little literature on sexuality and early childhood. That which exists tends 
to point in the direction of constructing children as being in need of protection, despite laws which uphold the competency and rights of young children. In the following sections, children's understandings of gender, sexuality and HIV/AIDS are addressed. Children, as will be demonstrated here, are neither innocent nor ignorant about HIV/AIDS and sex.

\subsection{Asserting the right to talk sexually about HIV/AIDS}

A dominant adult view in the construction of childhood is that children and sex should be kept apart. In contrast, discussions with seven- and eightyear-old children about their knowledge of HIV/AIDS shows how prominently sexual matters feature:

\begin{tabular}{|c|c|}
\hline Research & How exactly is HIV/AIDS spread? \\
\hline Mlondi: & By kissing [giggles]. \\
\hline Wendy: & $\begin{array}{l}\text { They're naughty [laughs]. They take } \\
\text { off their clothes and have sex. }\end{array}$ \\
\hline ros rab & : What's that? \\
\hline Wer & $\begin{array}{l}\text { It's when you are going to make a } \\
\text { child. }\end{array}$ \\
\hline Wendy: & By playing with boys. \\
\hline Nosiphu: & $\begin{array}{l}\text { Sleeping with him. People get } \\
\text { naughty in bed [laughs]. }\end{array}$ \\
\hline del & By not wearing a condom. \\
\hline
\end{tabular}

In these discussions, seven and eight year-olds connect HIV/AIDS with sex and sexual behaviour and in doing so transgress the myths of sexual innocence. Enabled by support from their peers, and accompanied by laughter, these children were able to talk about sex within the wider constraints of sexual taboos and in ways that enable them to insert themselves into a sexual culture. Laughter acquires a symbolic significance in this context. Not only does it allow for the validation and support of childhood sexual cultures, it also allows them to speak of transgression. Their knowledge about condoms does not simply break the myth of childhood innocence, but also provides the young children with awareness of the safety that the condom is supposed to provide against HIV/AIDS. But while children are asserting their right to know sexually and enjoy the conversation, judgement is also passed on sex as 'naughty'. The significance of sex as 'naughty' highlights the ways in which young children take the meaning of sex - as both pleasurable (using the logic of laughter) and naughty (adopting an adult stance). In other words, young children assert their rights to talk about HIV/AIDS sexually but also adopt adult stances on the matter, distancing and rejecting child sex. In this way, they adjust and accommodate children's rights to know sexually.

\subsection{Man-eaters: the gendering of HIV/AIDS and the violation of girls' rights}

It is widely acknowledged that gender is critical in understanding increased risk. In the next discussion, young girls show their vulnerabilities and demonstrate their lack of rights in contexts of violence and rape:

Phumzile: It's men that spread this disease, because we heard from women how it started. I know it's men, because usually they rape a girl, and go and keep changing and sharing this woman. And maybe she is already infected, and they go and rape other ones... Men. They rape and rape and don't care.

Researcher: What is rape?

Phumzile: Rape is AIDS.

Nomusa: When an older person calls you and does bad things to you ... he puts his penis in you ...

Nontobeko: When somebody eats people, he is a man-eater and gets HIV.

Researcher: Eats people? What do you mean by that?

Nontobeko: One old man from near where I stay - he always threatened us, he tells us that he eats kids. If he sees us wondering in the road, he will take one and eat and show them.

Phumzile: They want to rape the children.

Hlengiwe: Because I know that from experience, because when we were walking home with my friends and this guy he is a very old man he came after us, he was running after us; I don't know about my friends, but I fled home. One of them was nearly caught by this man. I know that he is not good.

Anele: $\quad$ Sometimes he buys us chocolate. Hlengive: We were a group of six and this same old guy came and bought us sweets. But we didn't eat them because our parents know about him; they said if anyone who give us something we must throw it away, and we always throw it away. 
Given the opportunity, the girls show how evocatively they can talk about their concerns and the limitations of their rights. UNAIDS (2005) asserts that in a number of countries HIV-positive women were found to be ten times more likely to have experienced male violence than those that are HIV-negative. Significantly the girls in this study point out that AIDS is rape. Sexuality is nuanced by other social differences. Within the context of danger and poverty in which they live, the young girls' sexualities are framed by the discourse of heterosexual danger (both real and imagined) - being vulnerable to HIV/AIDS, to older men and rape.

Unlike the previous section, where the children in the group demonstrated knowing about sexuality in emotively pleasurable ways, the discussion here is ominous and serious. The material and social circumstances in South Africa's townships make black girls more vulnerable to rape and abuse. The myth of cleansing HIV/AIDS by having sex with a virgin also underlies the concerns of young children. Given the legacies of apartheid, the history of inequalities, a violent and a highly patriarchal system of government, and the calamitous socioeconomic conditions in which black men continually are emasculated, it is no surprise that the girls are constructing their femininities and their sexualities by drawing upon discourses of fear of AIDS and men 'men who don't care' and who rape.

Without attempting to diminish the fear through which sexualities are being constructed and the vulnerabilities of girls, it is also important to understand that the master identity of dangerous sexuality is being deployed by the girls whose vulnerability and status as 'victims' is reinforced by parents who warn them of men.

\subsection{Resisting the right to know}

When young children were asked whether they should talk about HIV/AIDS in the classroom, the responses were overwhelming 'No', 'It wouldn't be right', 'Sex is not to be discussed by small children':

Researcher: Are we supposed to talk about AIDS? Nkanyiso: No.

Researcher: Why?

Nkanyiso: It doesn't make us feel good.

Researcher: Why?

Thabiso: We don't like talking about them.

Researcher: Why?
Mlungisi: We don't like to be taught bad things.

Silindile: It's not right.

Researcher: Why?

Mlungisi: We are going to do it too.

Researcher: You'll do it?

Silindile: Maybe a girl says to a boy, 'come and have sex with me'.

Nkanyiso: We'll get smacked ... by the teachers. Researcher: Why?

Silindile: Because it's old people's stuff.

By resisting the right to know about HIV/AIDS and about sex, the children were drawing upon discourses of childhood innocence despite the richness of their knowing. These contradictions show very clearly the constant struggle that young children have to endure in trying to present themselves as the ideal child. The deployment of childhood innocence is a strategic tool in the manufacture of the adult's version of childhood. To adopt the position of adult is to allow childhood innocence to flourish and to mark out hierarchies - those who assert the right to know suffer the effects of being excluded from the mythical (but powerful) version of childhood.

Discredited notions that children who know about sex do sex is also resurrected by Silindile, working to validate adult concerns about sexuality and young children. The rejection of the right to know and the negotiation around knowing is framed not only by dominant adult perceptions of childhood sexuality but also by the concrete knowledge that they will be 'smacked'. In South Africa corporal punishment has been banned since 1996, but its practice has not been completely eliminated as suggested by other research and by the children themselves (Deacon et al. 1999). Corporal punishment thus induces fear, and limits and represses their sexual voices.

\section{Conclusion}

Promulgating and enforcing the idea that children's rights are sexual rights will not in itself work, since children themselves are inserting discursively into their right to know, and speak sexually. In the South African context, it would be simplistic to assume that children are simply waiting for sexual rights to be realised. In contrast, this article has shown how they 'do' sexual rights and how these rights are marked by class/race and gender. It is through this complex matrix that rights are asserted, negotiated and rejected. Young children have an indefatigable sexual curiosity, but this is tempered, adjusted and 
negotiated. Their agency and thus the assertion and negotiation of their rights can be seen as shaped, created and constrained by their social contexts, but they too shape them and are enabled by them.

Complex social, cultural and economic forces in South Africa have shaped and are shaping the experience of sexuality and of sexual rights and these condition the possibility for agency. Issues of power, gender inequality and sexual oppression are increasingly important to young girls and boys in this study and an indication of their later risk. Young children position themselves and their knowledge in relation to the world of adults in ways that have an impact on their right to knowledge, information and their freedoms as in the example of associating the connections between sex and AIDS with 'old people's stuff'.

The freedom of young girls and their vulnerability to HIV shows in the performance of their sexuality framed by discourses of danger and fear that are

\section{References}

Deacon, R., Morrell, R. and Prinsloo, J. (1999)

'Discipline and Homophobia in South African

Schools: The Limits of Legislated Transformation', in

D. Epstein and J. Sears (eds), A Dangerous Knowing:

Sexual Pedagogy and Popular Culture, London: Casell

Department of Health (2005) Summary Report:

National HIV and Syphilis Antenatal Sero-prevalence

Survey in South Africa 2002, Republic of South

Africa: Department of Health, Health Systems

Research, Research Coordination and Epidemiology

James, A., Jencks, C. and Prout, A. (1998) Theorising

Childhood, Cambridge: Polity Press

Mitchell, C. and Smith, A. (2003) 'Sick of AIDS: Life,

Literacy and South African Youth', Culture, Health \& Sexuality 5.6: 512-22

O'Sullivan, L.F., Harrison, A., Morrell, R., Monroe-

Wise, A. and Kubeka, M. (2006) 'Gender

Dynamics in the Primary Sexual Relationships of

Young Rural South African Women and Men',

Culture Health and Sexuality 8.2: 99-113

Phillips, H. (2004) 'HIV/AIDS in the Context of South

Africa's Epidemic History', in D. Kauffman and intimately linked to the contexts in which they live their lives. Despite arguing that rights are an active realm of rejection, appropriation and assertion, young girls will have very little choice to exercise their autonomy in contexts of male violence; neither will boy as well as girl children have much choice in the context of corporal punishment.

South African HIV/AIDS has made the domain of sexual struggles more visible, and with it the possibility of child sex rights. Treating young children as speaking, knowing and experiencing sexual subjects, and taking their concerns, pleasures and fears seriously, as the research on which this article is based sought to do, can create the space to enable young children to recognise and exercise their rights. This points clearly to the need for sexual literacy and openness in early childhood education, and for children to be treated in a rights-respecting way - respecting their rights to think about sex and sexuality, their rights to talk about sex rights and their rights to act.

D. Lindaver (eds), Aids and South Africa: The Social Expression of a Pandemic, Basingstoke: Palgrave Macmillan

Prout, A. (2000) The Body, Childhood and Society, New York: St Martin's Press, Inc.

Renold, E. (2005) Girls, Boys and Junior Sexualities: Exploring Children's Gender and Sexual Relations in the Primary School, London: Routledge Falmer

Silin, J. (1995) Sex, Death and the Education of Children: Our Passion for Ignorance in the Age of AIDS, New York: Teachers College Press

UNAIDS (2005) UNAIDS in South Africa, www.unaids.org (accessed 31 March 2006)

UNICEF (2003) Human Rights Approach and Development Programming, Nairobi: UNICEF Waites, M. (2005) The Age of Consent. Young People, Sexuality and Citizenship, Basingstoke: Palgrave Macmillan

Weeks, J. (2000) Making Sexual History, Cambridge: Polity Press

Whiteside, A. and Sunter, C. (2000) AIDS: The Challenge for South Africa, Cape Town: Human \& Rousseau and Tafelberg 